阿尔泰地区可持续发展辅助决策平台与生态环境保护和生态城建设

崔伟宏, 蒋样明, 王拓

(中国科学院遥感与数字地球研究所, 北京, 中国)

wh8cui@163.com,jiangym@radi.ac.cn,wangtuo@radi.ac.cn

\title{
AUXILIARY DECISION-MAKING PLATFORM OF ALTAI REGION AND ECOLOGICAL ENVIRONMENT PROTECTION AND CONSTRUCTION OF ECO CITY
}

\author{
Cui Weihong, Jiang Yangming, Wang tuoPh \\ Institute of remote sensing and digital earth, \\ Chinese academy of sciences \\ Beijing, the People's Republic of China \\ wh8cui@163.com,jiangym@radi.ac.cn,wangtuo@radi.ac.cn
}

\begin{abstract}
Because of the lack of information sharing and multidisciplinary cooperation platform in Altai region, we will carry out the research on auxiliary decision-making platform, based on the sustainable development and the circular economy theory. So that we can finish the information management, query and decision analysis support of landform, climate, resources, nature reserves, cultural heritage and natural heritage, cattle ranches base and industrial park, etc.
\end{abstract}

Keywords: sustainable development; circular economy; auxiliary decision-making platform.

简介

生态环境日益恶化是当代人类面临的全球性问题之一。在严峻的生态危机面前, 必须寻求经济增长 模式的全面转变, 加强对其自然支持系统的保护与建设, 协调好人口、资源、环境与发展的矢系, 实现人 类社会可持续发展。中国科学院遥感与数字地球研究所经过 10 多年的科学研究, 在可持续发展、循环经济 、绿色经济、生态城建设基础理论与方法; 循环经济信息化、智能化、辅助决策支持系统等应用方面取得 了丰硕的科研成果。主要成果包括 :

1. 建立了循环经济基础理论与方法体系—

循环经济基础理论、发展循环经济运行模式、循环经济技术支持体系和静脉产业、循环经济的信息化框架 结构、清洁能源利用等；

2. 开发了区域可持续发展综合评价与系统集成平台—

分布式区域可持续发展信息系统、生态环境遥感监测与分析、土地资源定量评价与土地后备资源管理开发 分析、水资源优化管理模型与水资源综合利用决策支持、人口承载力分析系统、交通状况分析与可持续发 展分析、农业产业结构调整与可持续发展、国家社会发展综合实验区可持续发展决策支持系统等；

3. 建立了边境地区可持续发展信息方法体系—

俄罗斯南远东地区区域资源潜在动态矢联及其评估方法、中俄边境Pogranichny-

taipingling自然地理区域的景观功能分区、俄罗斯远东南部和中国东北（黑龙江流域）的土地利用开发趋势

4. 循环经济发展实践应用成果包括：“中新天津生态城”循环经济框架设计；南方经绸之路经济带 南腾冲新型城镇化建设; 湖北随州新型城镇化规划与建设; 黄准海地区可持续发展规划及信息化; 基于循 环经济理论的北京密云西田各庄的新农村建设; 蟹岛循环经济示范园区水资源的循环经济。

中国科学院遥感与数字地球研究所具备了上述理论研究和大量的应用实践。培养了一批中青年高层 次研究队伍。愿积极参加大阿尔泰国际合作项目,

主要研究目标和内容如下： 


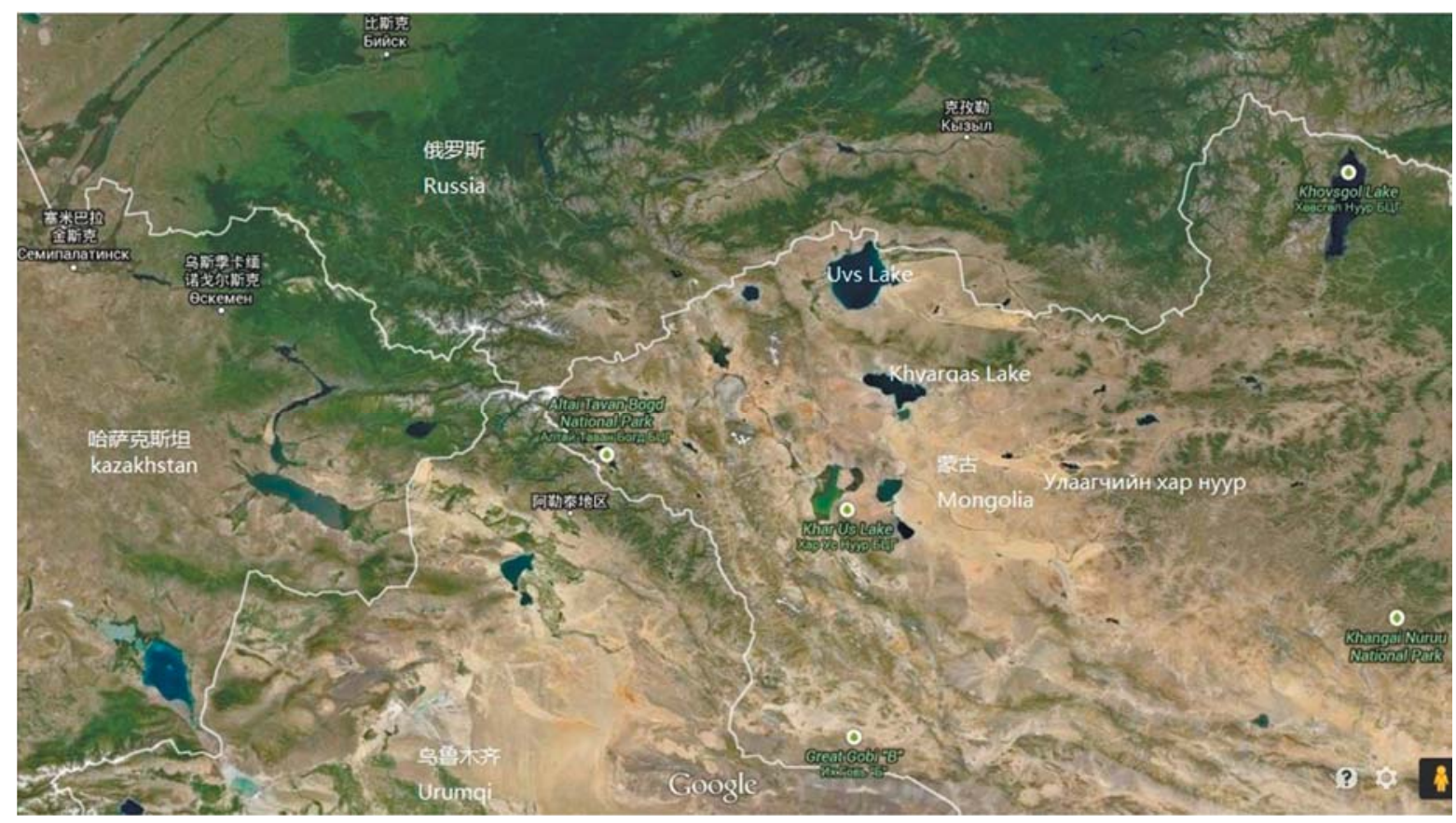

图1a 阿尔泰地区Google地图

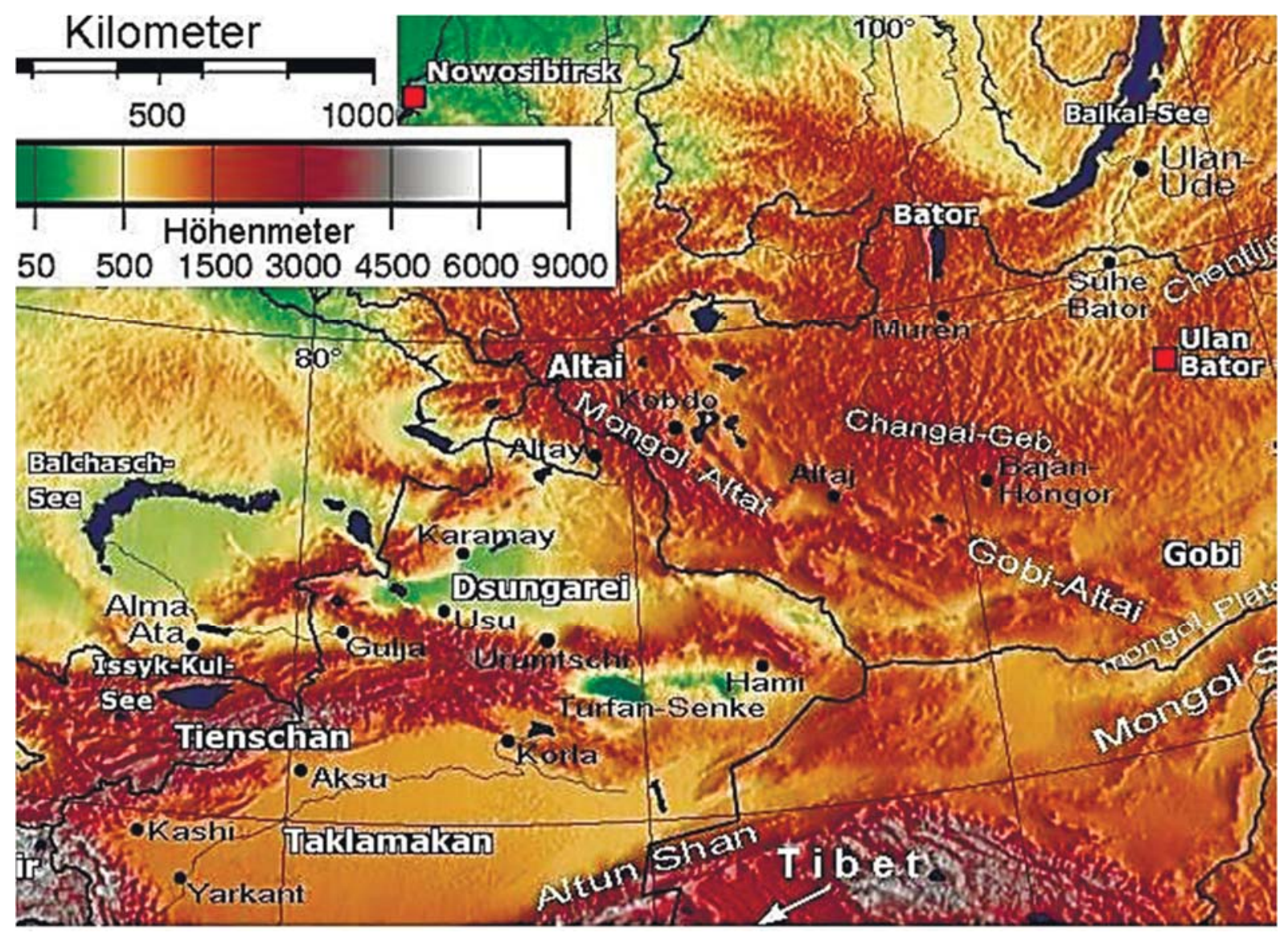

图1b阿尔泰地区地质构造图

研究目标

可持续发展信息系统包含了资源、环境、文化、人类社会有矢的经济、社会、科技、人口等信息， 它为实现国家与地区的可持续发展提供了重要支持与保障。通过参加“大阿尔泰地区的阿特拉斯：自然, 历 史, 文化”跨学科地图模型国际合作, 搭建阿尔泰地区可持续发展辅助决策系统平台, 实现对区域内地形、 地貌、冰川、气候、土壤、森林资源、草场资源、水资源、生物多样性资源、自然保护区、文化遗产、自 
然遗产、农牧场基地、工业园区等信息化管理、查询及决策分析支持。可以为阿尔泰地区可持续发展, 维 护中、俄、蒙、哈四国边境地区的和谐发展提供科学支持。

主要研究内容

基于可持续发展、循环经济理论, 开展阿尔泰地区可持续发展通用决策支持系统研究, 主要研究内

容包括：（1）阿尔泰地区可持续发展辅助决策支持系统的框架设计；（2）通用决策支持系统的时空信息 双向交互；（3）基于阿尔泰地区特色的生态城建设框架与顶层设计；（4）阿尔泰地区经济与贸易工业园 区合作平台。

阿尔泰地区可持续发展辅助决策支持系统的框架设计

阿尔泰地区可持续发展辅助决策支持系统是以管理科学、运筹学、控制学、信息论、信息经济学、 心理学、组织理论、人工智能等为基础, 以计算机技术、仿真技术、信息技术、数据仓库、数据挖掘、联 机分析处理、人工智能等为手段, 基于Internet网并支持各级规划部门研制发展规划的群体决策支持系统。 用户在该决策支持平台上能相互通信、数据共享、协同设计与综合决策分析, 对各种发展前景进行仿真及 预测。建立区域发展决策支持系统是提高区域发展决策水平的重要途径。核心内容包括：

1. 基于云计算技术的阿尔泰地区基础设施虚拟化、整合；

2. 基于智能体Agent的数据与模型集成 ;

3. 基于Agent的协同设计与集成;

4. 基于云计算技术的阿尔泰地区可持续发展信息共享 ;

5. 通用决策支持系统的数据挖掘与大数据分析 ;

6. 通用决策支持系统的仿真技术。

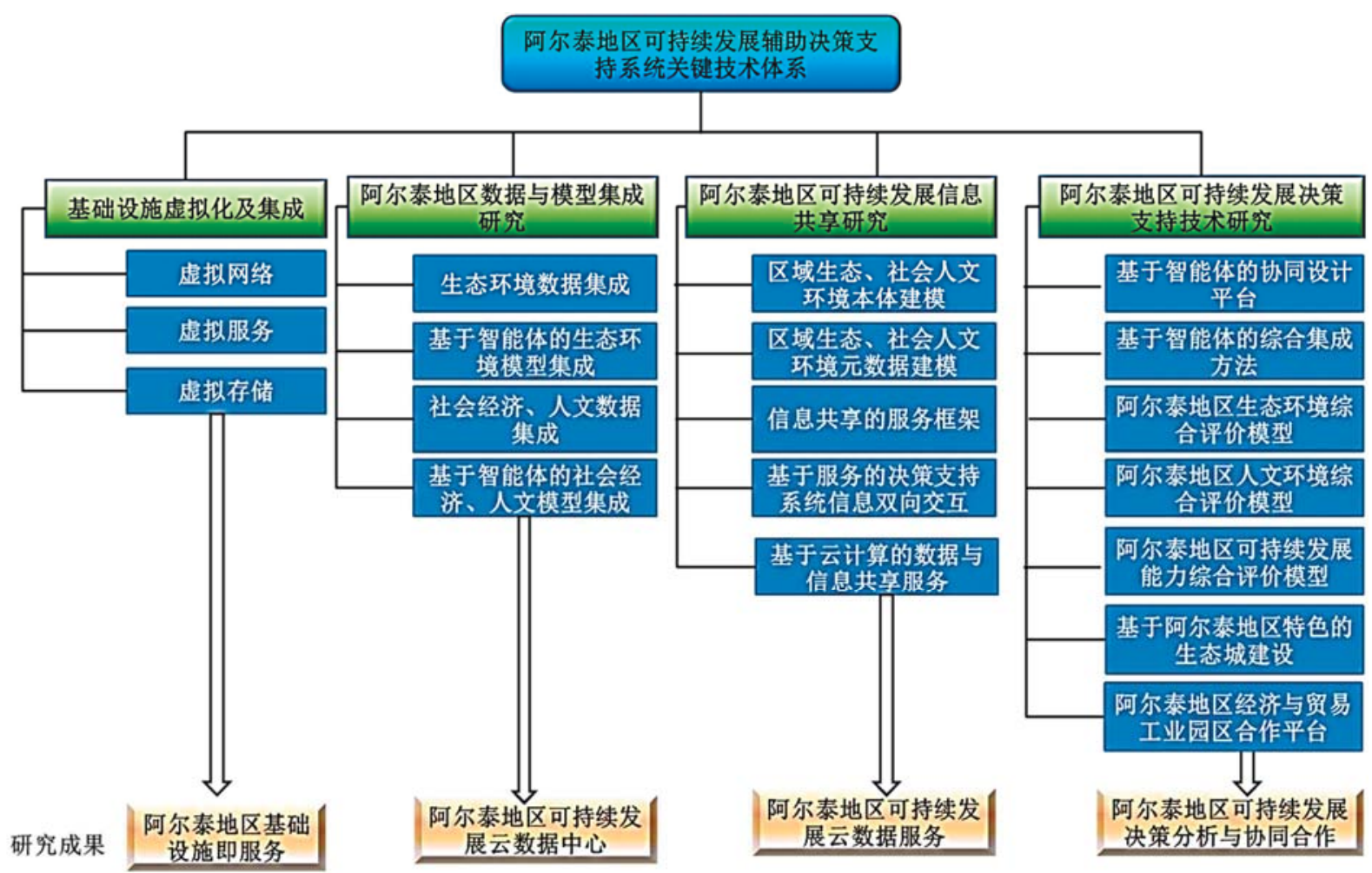

图2阿尔泰地区可持续发展辅助决策支持系统关键技术体系

通用决策支持系统的时空信息双向交互

采用基于云计算、面向服务方式, 开展通用决策支持系统的时空信息双向交互技术。主要包括：

1. 物联网多源异构时空信息交互

阿尔泰地区生态环境监测、气候环境监测以及日常生活中, 必将大量涉及到物联网技术的应用。物 联网多源异构时空信息交互技术的核心内容：

-物联网多源异构信息的语义知识表达、存储、语义互操作、信息共享等 ;

- 大规模无线感知网络的信息交互；

- 多媒体感知网络的信息交互。

2. 基于智能手机的时空信息双向交互 
基于智能手机的时空信息双向交互系统，支持用户自动采集与获取周边的人际信息、生态环境信息 。它具有网络自组织、不受基础设施的影响、可以直接感知用户当前的环境以及用户自身状态的特点。它 主要由两个部分组成：无线通信模块和信息处理与控制模块。

\section{3. 基于Android移动平台的时空信息交互}

主要通过基于

移动即时通信系统网络拓扑、即时通信系统客户端和服务器端功能、即时通信系统实现方式等研究, 完成A ndroid 移动平台的即时通信系统。

阿尔泰地区生态城建设框架与顶层设计

\section{1. 低碳智能生态城的基本思路}

低碳智能生态城本身就是一个包含自然、经济和社会的复合系统, 是以物联网及地球信息技术为基 础, 以低碳为核心, 以生态监测和预测为重点, 人与自然和谐、生态文明、资源节约、环境友好的社会经济-

自然的城市复合生态信息系统体系。相比传统城市的发展模式, 低碳智能生态城以复合生态系统和地球信 息科学为理论基础, 以物联网及地球信息技术为基础, 以低碳为核心, 以生态监测和预测为重点, 集居民 生活、工作、文化、休闲、服务为一体。通过对先进的电子商务、网络教育、远程服务、网络医疗、公共 交通、再生资源开发、清洁能源等技术的综合运用, 实现城市低碳、节能。

\section{2. 主要研究内容}

从生态细胞管理, 低碳智能生态城的基础信息体系, 数字低碳与数字生态环境体系, 数字社会服务 体系，数字低碳经济支持体系等方面提出低碳智能生态城的总体设计框架。

- 低碳智能生态城的概念模型

- 低碳智能生态城的总体设计框架

・低碳智能生态城综合分析与评估体系

- 生态细胞管理

・应用平台、数据和技术支持

阿尔泰地区经济与贸易工业园区合作平台

构建阿尔泰地区通用决策支持系统的经济与贸易工业园区合作平台，实现跟西安高新技术产业开发 区、西安现代农业开发区、中矢村科技园区、中国深圳市高新技术产业园区等重点经贸产业园的信息、经 济、贸易、科技等方面的信息资源共享与合作。有利于依托国际大通道、以重点经贸产业园区为合作平台 ，打造阿尔泰地区经济融合、文化包容的国际经济合作走廊。

阿尔泰地区经济与贸易工业园区合作平台主要包括：阿尔泰地区国际经贸工业园区数据服务中心 、 重点经贸工业园区国际合作交流平台、国际科技合作交流平台、国际贸易服务平台、国际贸易信用保险平 台、中小企业融资担保平台、海外买家信息平台、电子商务平台、物流平台、一站式服务平台（对内对外 签订协议、审核信用证、收汇结汇、报矢、报检、租船订舱、外汇核销、出口退税等）。

阿尔泰地区经济与贸易工业园区合作平台将在以下方面发挥重要作用 : 为提升多边合作水平注入了 新动力, 优化产业结构, 推进科技创新, 充分发挥各国生产、加工、科技等方面的特色, 为双方务实合作 带来新的增长点; 突出区域可持续发展战略性重点领域; 培育新的合作亮点, 进一步挖掘潜力, 探索新的 领域; 扩大地方合作交流, 有利于夯实多边经贸合作的基础, 开拓阿尔泰地区各国全方位、多领域合作的 空间。

\section{阿尔泰地区可持续发展决策分析应用系统}

构建阿尔泰地区可持续发展决策支持系统，实现对阿尔泰地区的自然资源、矿产资源、能源资源、 土地资源和旅游资源进行综合评估分析, 根据当地的资源禀赋, 为可持续发展提供决策依据。主要功能模 块有:

1. 阿尔泰地区生态安全评估与生态安全维护、修复

- 阿尔泰地区生态安全监测、评估与标准体系;

- 阿尔泰地区生态安全等级空间分布与分类专题图；

- 建立阿尔泰地区生态修复方法体系及模拟系统；

- 生态维护、生态修复可持续发展决策方案分析。

2. 阿尔泰地区资源管理数据库与评估系统

- 建立阿尔泰地区资源管理数据库与评估系统；

- 建立资源开发影响区域的自然-生态和社会-经济评估方法和绘图方法 ;

- 建立资源可持续发展的重要指标；

- 获得资源开采的生态安全、可利用性、可持续开发程度等级；

- 评估和绘制阿尔泰地区自然环境和资源；

3. 阿尔泰地区资源开采的生态安全、可持续发展评估 
利用空间遥感监测和地面监测相结合的方法, 对阿尔泰地区生态环境系统进行动态监测, 以分析生 态环境利用现状、变化状况以及人类活动对生态系统造成的压力和影响; 获得资源开采的生态安全、可利 用性、可持续开发程度等级。

4. 建立阿尔泰地区城镇化、沙草产业等生产要素数据库

促进阿尔泰地区生态环境与经济可持续发展合作建议

参加俄罗斯、哈萨克斯坦、中国、蒙古“大阿尔泰地区的阿特拉斯：自然，历史，文化”跨学科地图 模型国际合作项目，主要合作内容建议：

1. 大阿尔泰地区通用决策支持系统的分布式、异构数据库建设方法研究

应用虚拟技术、云计算技术集成阿尔泰地区的基础设施（计算机资源、服务器资源、存储设备等） , 提供基础设施即服务; 构建阿尔泰地区的云数据中心，为阿尔泰地区可持续发展提供可靠的、及时的、 精确的空间信息以及自然、历史、文化数据。

\section{2. 大阿尔泰地区通用决策支持系统的大数据分析方法研究}

通过可视化分析（Analytic Visualizations）、数据挖掘算法（Data Mining Algorithms）、预测性分析能力 (Predictive Analytic Capabilities) 、语义引擎 (Semantic Engines）、数据质量和数据管理（Data Quality and Master Data Management) 研究, 实现对阿尔泰地区可持续发展海量数据进行大数据分析研究, 进行直观数据展示与模拟预测 , 为阿尔泰地区发展规划提供数据支持。

3. 大阿尔泰地区辅助决策支持系统的集成・协同方法研究

通过阿尔泰地区辅助决策支持系统的协同设计与集成平台研究，集成各种现有工具软件系统、地理 信息系统、数据库系统等, 为中、俄、哈、蒙各国政府、跨区域经贸园区、企业、多学科专家, 异地、并 行参与战略合作、区域可持续发展规划设计、企业跨国合作生产、虚拟企业构建等提供支持。

\section{4. 大阿尔泰地区的地球系统科学、可持续发展理论与方法研究}

坚持发展绿色经济, 切实树立生态环境与经济协调发展观念; 加强信息化建设、优化产业结构, 发 展循环经济与产业园区; 加强阿尔泰地区生态环境监测、分析、评估与综合治理 ; 建立并完善生态补偿机 制、综合决策分析机制, 完善经济与环境和谐发展机制。 